\title{
A blueprint for maternal and child health primary care physician education in medical genetics and genomic medicine: Recommendations of the United States Secretary for Health and Human Services Advisory Committee on Heritable Disorders in Newborns and Children
}

\author{
Alex R. Kemper, MD, MPH, MS ${ }^{1}$, Tracy L. Trotter, $M D^{2}$, Michele A. Lloyd-Puryear, MD, PhD ${ }^{3}$, \\ Penny Kyler, $M A^{3}, W$. Gregory Feero, $M D, P h D^{4}$, and R. Rodney Howell, $M D^{5}$
}

\begin{abstract}
Primary health care providers will play an increasingly important role in delivering genetics-related services for women and children along the reproductive continuum. However, most primary health care providers have received little training in genetics or medical genomics to incorporate such services into routine care. A workshop was convened by the National Institutes of Health, the Centers for Disease Control and Prevention, and the Health Resources and Services Administration to identify practical strategies to educate primary care physicians involved in maternal and child health. These included developing a targeted curriculum for residency training programs, incorporating assessments of genetics and genomic medicine into the initial board certification process and the process for maintenance of certification, providing continuing medical education opportunities at national meetings, establishing an Internet-based repository of recommendations for primary care providers, and forming a learning collaborative to link primary care providers and specialists to evaluate strategies to improve care. Workgroup members underscored the importance of assessing the impact of these interventions on the process and outcomes of health care delivery. The recommendations from this workshop were presented to the United States Secretary for Health and Human Services' Advisory Committee on Heritable Disorders in Newborns and Children Subcommittee on Education and Training. The Subcommittee reviewed the report and put forth recommendations to the Committee, which were adopted by the Committee in September 2009. Genet Med 2010:12(2):77-80.
\end{abstract}

Key Words: education, medical, genetics, primary health care, maternal health services, child health services

\footnotetext{
From the ${ }^{1}$ Department of Pediatrics and Duke Clinical Research Institute, Duke University, Durham, North Carolina; ${ }^{2}$ San Ramon Valley Primary Care Medical Group, San Ramon, California; ${ }^{3}$ U.S. Department of Health and Human Services, Health Resources and Services Administration, Washington, DC; ${ }^{4}$ U.S. Department of Health and Human Services, National Institutes of Health, Bethesda, Maryland; and ${ }^{5}$ Department of Pediatrics, Miller School of Medicine, University of Miami, Miami, Florida.

Alex R. Kemper, MD, MPH, MS, Department of Pediatrics and Duke Clinical Research Institute, Duke University, 2400 Pratt Street, Room 0311 Terrace Level, Durham, NC 27705. E-mail: alex.kemper@duke.edu.

The views expressed in this article are those of the authors and do not necessarily reflect those of the authors' respective agencies within the U.S. Department of Health and Human Services.

Disclosure: The authors declare no conflict of interest

Submitted for publication October 16, 2009.
}

Accepted for publication November 17, 2009

Published online ahead of print January 15, 2009

DOI: $10.1097 /$ GIM.0b013e3181cb78fa
Ensuring adequate primary care health care provider knowlE edge about medical genetics and the role of genomic medicine is important to provide high quality care for women and children along the reproductive continuum. At the most basic level, family health history is a core component of preventive care. ${ }^{1,2}$ Genetic screening has an increasingly prominent role in primary care. For example, preconception and prenatal screening is recommended for a wide array of conditions such as cystic fibrosis ${ }^{3}$ and Down syndrome, ${ }^{4}$ and nearly all of more than 4 million newborns in the United States are tested for 29 or more conditions. ${ }^{5}$ In fact, newborn screening is the largest coordinated genetic screening program in the United States.

Genetic screening activities present many challenges to primary care providers, including the need to educate patients and their families about the role of screening, to explain the meaning of a positive result, to coordinate diagnostic testing, and to assure appropriate follow-up. Because newborn screening is a public health service available to all newborns before discharge from the birth hospital, the challenges faced by primary care providers related to newborn screening are somewhat different than preconception or prenatal screening. For example, in preconception and prenatal screening, health care providers must systematically identify individuals for screening and know which screening tests to order and how to interpret their results. ${ }^{6}$

Advances in medical genetics and genomic medicine will revolutionize care, both through improvements in the detection and treatment of fetuses, newborns, and children with genetic disorders and improvements in the health outcomes for women and children with a broad array of other health conditions through personalized medicine. ${ }^{7}$ Examples include preconceptual, prenatal, or postnatal screening for Fragile X syndrome ${ }^{8}$; identification of risk for diabetes ${ }^{9}$; and the use of pharmacogenomic strategies to optimize the treatment of asthma. ${ }^{10}$ Findings that result from testing during prenatal care or newborn screening can have implications for women and families, including opportunities to improve their own health or engage in reproductive planning. Primary care health providers serve on the frontline of care and often care for several members of a family, offering the opportunity to consider the family health history in its entirety. Since there is a significant workforce shortage of clinical geneticists, ${ }^{11}$ by necessity, primary care providers will need to be knowledgeable about fundamental issues in medical genetics and be prepared to practice genomic medicine.

Significant barriers currently prevent the adoption of medical genetics and genomic medicine into primary care. Although recent genetic discoveries offer important and exciting avenues for improving health outcomes, few studies have explored how these advances might be incorporated into routine care. ${ }^{12}$ The 
National Institutes of Health's recent emphasis on clinical translational research ${ }^{13}$ will likely lead to the rapid development of new clinical recommendations. Primary care physicians already face significant time pressures to comply with a plethora of current practice guidelines and administrative necessities. ${ }^{14}$ Electronic medical records and other clinical information systems may help improve the overall efficiency of care and will be critical for our eventual integration of personalized medicine in routine practice. Fundamentally, however, advances in medical genetics and genomic medicine will not be incorporated into primary care practice if primary care providers do not appropriately prepare themselves. Unfortunately, many primary care providers lack knowledge, training, experience, and confidence in providing genetics-based services, ranging from understanding of basic genetics to collecting and interpreting family health histories and to ordering, interpreting, and acting on genetic tests. ${ }^{15}$

\section{Workshop}

To develop a strategy for incorporating genetics and genomic medicine into routine primary care, the National Institutes of Health, the Centers for Disease Control and Prevention, and the Health Resources and Services Administration convened a 2-day meeting in June 2009. This report summarizes the second day of this meeting, which focused on the incorporation of genetics and genomic medicine into maternal and child health care. Workshop attendees (see Appendix) included representatives of the organizations convening the meeting, representatives from organizations representing primary care providers (the American College of Medical Genetics, American Academy of Pediatrics, American Academy of Family Physicians, and American College of Obstetrics and Gynecology), primary care providers, clinical researchers, geneticists, and representatives from the Physician Assistant Education Association and the March of Dimes. Two areas were discussed: (1) the educational needs of primary care providers to incorporate genomic medicine into routine care over the next 5 years; and (2) the barriers that impede primary care providers from learning how to provide genomic medicine. The meeting concluded with the development of an action plan to educate primary care providers in genomic medicine. The workgroup's recommendations were subsequently reviewed and endorsed by the United States Secretary for Health and Human Services Advisory Committee on Heritable Disorders in Newborns and Children (Advisory Committee).

\section{Educational needs of primary care providers}

Workshop participants identified a central theme: primary care providers often underestimate the degree to which genetics and genomic medicine play a role in the health of their patients. Instead of compartmentalizing genetics and genomic medicine within the context of certain conditions, health care providers should consider the role of genetics and genomic medicine in each clinical encounter. Although content knowledge is important for the management of specific conditions, the rapid growth of information generally does not allow primary care providers to be content experts. Primary care providers should recognize that genetics and genomic medicine will be an integral component of care and should develop an effective strategy for incorporating emerging clinical genetic medicine recommendations into their clinical practice.

The workgroup then developed a list of specific knowledge areas for maternal and child health primary care providers. This list was informed by the ongoing activities of the National
Coalition for Health Professional Education in Genetics to develop core competencies in genetics. ${ }^{16}$

- Genetics and genomic medicine literacy, including understanding of basic terminology, types of mutations, and how genes and the environment can interact to affect health;

- The interpretation of clinical utility of genetic tests;

- The role of primary care providers in newborn screening;

- How to collect, document, and act on a family health history across the lifespan of a woman and her family;

- Sources for guidelines and clinical recommendations for genetics and genomic medicine in primary care;

- Methods of informing families about genetic testing and obtaining consent;

- How to communicate information about risk of conditions to women before pregnancy and when pregnant; and

- When and how to refer families to a genetic counselor or geneticist.

\section{Barriers to educating primary care providers in genomic medicine}

Education related to genetics and genomic medicine should begin in medical school. However, the knowledge areas highlighted by the workgroup must be included in postgraduate training. The workgroup separately considered barriers to educating those in training and those already in practice. For both groups, the lack of time for formal educational opportunities was considered to be the most important barrier. Workgroup members also recognized that many residency training programs do not have geneticists who could provide the appropriate educational guidance, mentoring, and curricular oversight. These barriers are magnified for those already in practice. The workgroup also acknowledged that lack of enthusiasm about genetics and genomic medicine among both trainees and those already in practice may significantly limit the effectiveness of educational efforts. This lack of enthusiasm is believed to reflect poor genetics and genomic medicine literacy and lack of certainty and confidence in providing genetic and genomic medicine services. Ironically, it may be that trainees and practicing providers may have such limited genetic literacy that they are hindered in the ability to recognize the exciting and progressive opportunities that genomic medicine offers for their patients and their own professional satisfaction.

\section{Blueprint for education}

The workgroup members recognized the importance of incorporating genetics and genomic medicine as a component of education in all aspects of clinical training. To address the lack of well-trained and available experts both within academic training centers and in the community, the workgroup made the following recommendations:

- Development of a genetics and genomic medicine educational curriculum that could be incorporated into residency training programs. The educational material should be case based and present common genetic concepts. Four particular scenarios were suggested for initial development of the educational material: a child with a positive newborn bloodspot screen; a child who has a positive newborn hearing screen; evaluation of a child with developmental delay or mental retardation; and a child with a family history of sudden cardiac death. Separate scenarios would need to be developed to address prenatal care.

- Ensuring that board certification exams assess knowledge related to the core educational goals, including basic liter- 
acy in genetics and genomic medicine. As with the residency training program educational material, the board certification process should be case based and address general concepts.

- Having continuing medical education available at national meetings and through the Internet that focuses on the practical aspects of incorporating genetics and genomic medicine into primary care, with a special focus on useful skills (e.g., obtaining a family health history and identifying "red flags" and when to refer for genetic counseling).

- Promote participation in genetics and genomic medicinerelated educational activities through the maintenance of board certification process. As examples of maintenance of board certification activities, the workgroup members recommended quality improvement modules focusing on prenatal screening, newborn screening, and family health history.

- Create a web site that would organize both clinical recommendations and practical office tools (e.g., family health history forms and risk questionnaires) to facilitate incorporation of genetic and genomic medicine into routine practice.

These recommendations are practical, feasible, and could be accomplished in 2 years with appropriate funding and support from the specialty organizations. The workgroup strongly recommended that these steps be tied to prospective evaluations to assure improvements in both the process of health care delivery and outcomes and changes in maternal and child health outcomes.

The workgroup members also recognized that few data exist to guide the incorporation of medical genetics and genomic medicine into the "real world" primary care setting. To understand barriers to and facilitators of genetics and genomic medicine into primary care and to gather data about health care providers' educational needs, the workgroup endorsed the development of a "learning collaborative" 17 by pairing representatives from busy primary care practices with genetics and genomic medicine through the formation of a Genetics in Primary Care Training Institute, which would provide the following services:

- All primary care providers would attend a conference to define opportunities for genetics and genomic medicine in primary care.

- Each primary care provider would be paired with an expert in genetics and genomic medicine to develop a specific 1 -year project for their practice with measurable outcomes in changes in the process of health care delivery. The Institute would facilitate the development of these projects.

- Members of the learning collaboratives would participate in at least bimonthly calls to review their progress.

- At the end of the first year of projects, the learning collaboratives will meet again in person to share results.

- The Institute would conduct formal evaluations of the impact of these projects. These formal evaluations will be used to update the other proposed activities and serve to begin the process of broader dissemination.

- Subsequent meetings and rounds of projects will be based on the results of the first round.

The workgroup recommended that there be a competitive process to host the Genetics in Primary Care Training Institute. This Institute could be housed within an organization that represents primary care providers or genetic medicine specialists, nonprofit organizations, or academic medical centers.

\section{ACKNOWLEDGMENTS}

Dr. Kemper's effort was supported from a subcontract to Duke University under prime contract (HHSP23320045014XI) to Altarum Institute from the Maternal and Child Health Bureau (Title V, Social Security Act), Health Resources and Services Administration, U.S. Department of Health and Human Services.

\section{REFERENCES}

1. Dolan SM, Moore C. Linking family history in obstetric and pediatric care: assessing risk for genetic disease and birth defects. Pediatrics 2007;120: S66-S70.

2. Guttmacher AE, Collins FS, Carmona RH. The family history-more important than ever. $N$ Engl J Med 2004;351:2333-2336.

3. Committee on Genetics, American College of Obstetricians and Gynecologists. ACOG Committee Opinion. Number 325, December 2005. Update on carrier screening for cystic fibrosis. Obstet Gynecol 2005;106: 1465-1468.

4. ACOG Committee on Practice Bulletins. ACOG Practice Bulletin No. 77: screening for fetal chromosomal abnormalities. Obstet Gynecol 2007;77: 217-228.

5. Watson MS, Mann MY, Lloyd-Puryear MA, Rinaldo P, Howell RR. Newborn screening: toward a uniform screening panel and system-executive summary. Genet Med 2006;8:1S-11S

6. Morgan MA, Driscoll DA, Mennuti MT, Schulkin J. Practice patterns of obstetrician-gynecologists regarding preconception and prenatal screening for cystic fibrosis. Genet Med 2004;6:450-455.

7. Ginsburg GS, McCarthy JJ. Personalized medicine: revolutionizing drug discovery and patient care. Trends Biotechnol 2001;19:491-496.

8. Bailey DB, Armstrong D, Kemper AR, Skinner D, Warren SF. Supporting family adaption to presymptomatic and "untreatable" conditions in an era of expanded newborn screening. J Pediatr Psychol 2009;34:648-661.

9. Kupila A, Keskinen P, Simell T, et al. Genetic risk determines the emergence of diabetes-associated autoantibodies in young children. Diabetes 2002;51:646-651

10. Koster ES, Raaijmakers JA, Koppelman GH, et al. Pharmacogenetics of anti-inflammatory treatment in children with asthma: rationale and design of the PACMAN cohort. Pharmacogenomics 2009;10:1351-1361.

11. Cooksey JA, Forte G, Flanagan PA, Benkendorf J, Blitzer MG. The medical genetics workforce: an analysis of clinical geneticist subgroups. Genet Med 2006;8:603-614.

12. Khoury MJ, Gwinn M, Yoon PW, Dowling N, Moore CA, Bradley L. The continuum of translation research in genomic medicine: how can we accelerate the appropriate integration of human genome discoveries into health care and disease prevention? Genet Med 2007;9:655-674.

13. Zerhouni EA. Translational research: moving discovery to practice. Clin Pharmacol Ther 2007;81:126-128.

14. Yarnall KSH, Pollak KI, Ostbye T, Krause KM, Michener JL. Primary care: is there enough time for prevention? Am J Public Health 2003;93:635-641.

15. Suther $\mathrm{S}$, Goodson P. Barriers to the provision of genetic services by primary care physicians: a systematic review of the literature. Genet Med 2003;5: $70-76$.

16. National Coalition for Health Professional Education in Genetics. Core Competencies in genetics for health professionals. Available at: http:// www.nchpeg.org/core/Core_Comps_English_2007.pdf. Accessed October 14, 2009.

17. Young PC, Glade GB, Stoddard GJ, Norlin C. Evaluation of a learning collaborative to improve the delivery of preventive services by pediatric practices. Pediatrics 2006;117:1469-1476.

\section{APPENDIX: WORKSHOP PARTICIPANTS}

The following is a list of workshop participants and the agencies or organizations they represented at the meeting. Being listed as a participant does not imply that the individuals or the organization that they represent endorses all aspects of this report.

Myles B. Abbott, MD, American Academy of Pediatrics

Mark W. Babyatsky, MD, American College of Physicians

Alice S, Bailey, National Human Genome Research Institute

Steven Berley, DO, American Osteopathic Association

Colleen Bucchner, MS, National Newborn Screening and Genetics Resource Center

Doug Campos-Outcalt, MD, MPA, American Academy of Family Physicians 
Frederick Chen, MD, MPH, American Academy of Family Physicians, Secretary of Health and Human Services Advisory Committee on Heritable Disorders in Newborns and Children

David C. Dale, MD, American College of Physicians

Siobhan Dolan, MD, MPH, March of Dimes

W. Gregory Feero, MD, PhD, National Human Genome Research Institute

Timothy Geleske, MD, American Academy of Pediatrics, Secretary of Health and Human Services Advisory Committee on Heritable Disorders in Newborns and Children

Constance Goldgar, MS, PA-C, Physician Assistant Education Association

Anthony R. Gregg, MD, American College of Obstetrics and Gynecology

Alan Guttmacher, MD, National Human Genome Research Institute

Ahmed A. K. Hasan, MD, PhD, National Heart, Lung, and Blood Institute

Brian Haugen, $\mathrm{PhD}$, Eunice Kennedy Shriver National Institute of Child Health and Human Development

R. Rodney Howell, MD, Eunice Kennedy Shriver National Institute of Child Health and Human Development, Secretary of Health and Human Services Advisory Committee on Heritable Disorders in Newborns and Children

Jean F. Jenkins, RN, PhD, National Human Genome Research Institute

Steven Keiles, MS, National Society of Genetic Counselors

Alex R. Kemper, MD, MPH, MS, Duke University Department of Pediatrics
Penny Kyler, MA, Genetic Services Branch, Maternal and Child Health Bureau, Health Resources and Services Administration

Leonard A. Levy, DPM, MPH, American Association of Colleges of Osteopathic Medicine

Michelle A. Lloyd-Puryear, MD, PhD, Genetic Services Branch, Maternal and Child Health Bureau, Health Resources and Services Administration

Alexander Lynch, Secretary of Health and Human Services Advisory Committee on Genetics, Health, and Society

Scott D. McLean, MD, Clinical Geneticist, Red Herring Genetics, San Antonio, TX

Jana Monaco, Secretary's Advisory Committee on Heritable Disorders in Newborns and Children

Thomas Musci, MD, American College of Obstetrics and Gynecologists, Secretary of Health and Human Services Advisory Committee on Heritable Disorders in Newborns and Children

Melissa Parisi, MD, PhD, Eunice Kennedy Shriver National Institute of Child Health and Human Development

Michael A. Rackover, PA-C, MS, National Human Genome Research Institute

P. Preston Reynolds, MD, PhD, Society of General Internal Medicine

Genevieve Swift, Eunice Kennedy Shriver National Institute of Child Health and Human Development

Tracy L. Trotter, MD, Secretary of Health and Human Services Advisory Committee on Heritable Disorders in Newborns and Children

Jeff Whittle, MD, MPH, Society of General Internal Medicine Amy Woodward, Society of General Internal Medicine 